\title{
The Transferability of Primary Child Healthcare Systems
}

\author{
Paul Kocken, Eline Vlasblom, Gaby de Lijster, Helen Wells, \\ Nicole van Kesteren, Renate van Zoonen, Kinga Zdunek, \\ Sijmen A. Reijneveld, Mitch Blair and Denise Alexander
}

\begin{abstract}
There is considerable heterogeneity between primary care systems that have evolved in individual national cultural environments. Models of Child Health Appraised (MOCHA) studied how the transfer of models or their individual components can be achieved across nations, using examples of combinations of settings, functions, target groups and tracer conditions. There are many factors that determine the feasibility of successful transfer of these from one setting to another, which must be recognised and taken into account. These include the environment of the care system, national policy-making and contextual means of directing population behaviour in the form of penalties and incentives, which cannot be assessed or expected to work by means of rational actions alone. MOCHA developed a list of criteria to assess transferability, summarised in a population characteristics, intervention content, environment and transfer (PIET-T) process. To explore the process and means of transferability, we obtained consensus statements from the researchers on optimum model scenarios and conducted a survey of stakeholders, professionals and users of children's primary care services that involved three specific health topics: vaccination coverage in infants, monitoring of a chronic or complex condition and early recognition of mental health problems. The results give insight into features of transferability - such as the availability and the use of guidelines and formal procedures; the barriers and facilitators of implementation and similarities and differences between model practices and the existing model of child primary care in the country. We found that
\end{abstract}

(C) European Commission. Published by Emerald Publishing Limited. This chapter is published under the Creative Commons Attribution (CC BY 4.0) licence. Anyone may reproduce, distribute, translate and create derivative works of this chapter (for both commercial and non-commercial purposes), subject to full attribution to the original publication and authors. The full terms of this licence may be seen at http://creativecommons.org/licences/by/4.0/legalcode 
successful transfer of an optimal model is impossible without tailoring the model to a specific country setting. It is vital to be aware of the sensitivity of the population and environmental characteristics of a country before starting to change the system of primary care.

Keywords: Transferability; implementation; model health services; health systems; child health; incentives

\section{Introduction}

The goal of the Models of Child Health Appraised (MOCHA) project is to define optimal models of primary child health care that have the potential of transfer to European Union (EU) countries. As we have seen, a model is only a simplified representation of a complex reality; however, the design of models of primary child health care is not a simple task because of the comprehensiveness of the componentry of healthcare systems (see Chapter 1). In this chapter, we study how the transfer of models of primary child health care can be achieved across nations, using examples of combinations of settings, functions and target groups. Tracer conditions we use to illustrate the options for transfer are preventive services for immunisation, treatment and monitoring of a chronic (asthma) or complex condition (traumatic brain injury), assessment of mental health problems of psychosocial and assessment of mental health problems, and psychosocial assessment of adolescents for use of contraceptive services. These topics will be dealt with, using the framework developed by MOCHA to analyse the complex primary care systems and assess criteria for transferability.

To understand the structure, processes and outcome of care delivery, a usable set of primary care systems' components was distinguished by Kringos, Boerma, Hutchinson, Van der Zee, and Groenewegen (2010), including governance, economic conditions, workforce, access, comprehensiveness, continuity and coordination, quality, efficacy and equity. MOCHA chose the components access and workforce to categorise the primary child healthcare systems according to roughly two system structure components: the primary care lead practitioner, being a general practitioner (GP) or paediatrician, and referral processes to secondary or other care (gatekeeping or not) (Blair, Rigby, \& Alexander, 2017). Combining the two components led to the following classification of primary care in EU countries:

- open access countries: countries with an open access referral process and any lead practitioner;

- gatekeeper and mixed-led countries: countries with a partial or usual gatekeeper and either a paediatrician-led primary care, or a mix of paediatricianled and GP-led primary care; and

- gatekeeper and GP-led countries: countries with a partial or usual gatekeeper and primary care led by a GP. 
The feasibility of the transfer of models from one setting to another is determined by many factors related to the population of a country, the characteristics of the model to be transferred and factors in the environment of the care system, including national policy-making and contextual means of directing population behaviour, such as penalties and rewards, called 'levers'. Keeping in mind the differences in care systems, the transfer of a model from one country to another requires tailoring to the specific country-setting. MOCHA has developed a long list of criteria for assessing transferability, summarised in a population characteristics, intervention content, environment and transfer (PIET-T) process model as shown in Figure 16.1 (Schloemer \& Schröder-Bäck, 2018). The criteria match with models on intervention implementation (Damschroder et al., 2009; Fleuren, Wiefferink, \& Paulussen, 2004). This is also discussed in detail in Chapter 18.

Understanding the significance of the PIET-T criteria is essential to successfully assess whether components of a model can be transferred to a different system. The next sections will assess feasibility of scenarios for improvement of primary care according to professional stakeholders from EU countries, expert views on implementation of good practices and legitimacy of levers - penalties and rewards - to achieve behaviour change.

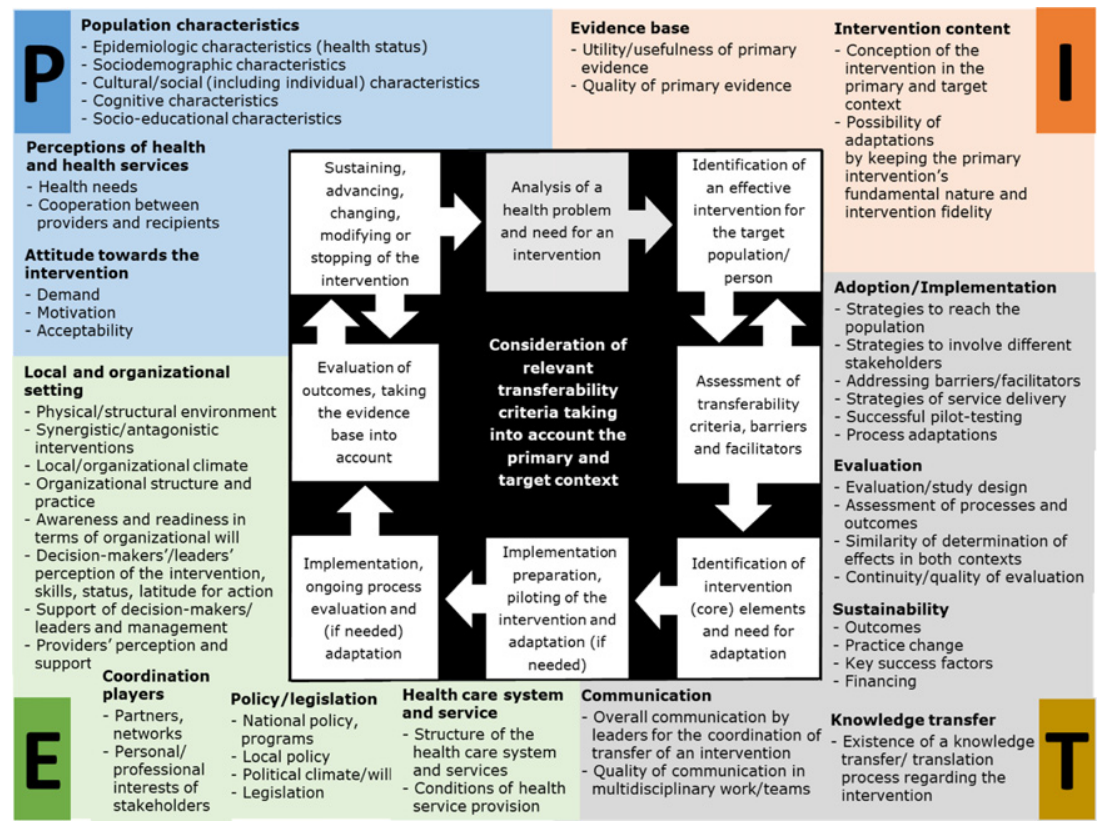

Figure 16.1. The PIET-T model with systematised criteria to determine transferability. 


\section{Listening to Professional Stakeholders}

We undertook a study to obtain consensus statements from stakeholders in children's primary health care on what needs to change to optimise primary care health systems for children. They were asked about the acceptability and feasibility of changes towards potentially optimal ways to deliver primary care to children and how these potential changes might be achieved. Testimonials and opinions from experts in the fields of policy-making, practice, science and knowledge, and end-user advocacy were gathered via a survey and online focus groups. As a stimulus for discussion, we created imaginary scenarios on future provision of child health care (Kocken, Vlasblom, De Lijster, \& Reijneveld, 2018).

The survey contained three health topics, accompanied by scenarios related to functions of primary child health care, the tracer conditions and children's age-groups. These topics were designed to reflect the comprehensiveness of a primary healthcare system for children:

- vaccination coverage in infants: prevention/ immunisation against measles/ 0-4 years old;

- treatment and monitoring of a chronic or complex condition: chronic care and complex care/asthma or traumatic brain injury/4-12 years old; and

- early recognition of mental health problems: school and adolescent health services/mental health/12-18 years old.

\section{Vaccination Coverage in Infants}

The stakeholder respondents considered a change of the care system's component 'public access to trustworthy information' as important. They called for more public information about vaccinations, to reduce vaccination hesitancy and thereby improving vaccination coverage in the population. Although the majority of stakeholders were positive about a scenario describing a specialised preventive child health service to improve vaccination coverage, a change from the current model in their country to any other was not given as a priority. A higher priority was given to combat vaccination hesitancy using public information. The stakeholders suggested the use of social media and opinion leaders to influence public opinion, even though literature suggests that combatting vaccination hesitancy through public information is less effective than providing information on vaccinations within an ongoing relationship between a specialised preventive child health professional and parents (Schollin Ask et al., 2017).

\section{Treatment and Monitoring of a Chronic or Complex Condition}

Almost all of the respondents were in favour of working in multidisciplinary teams to improve care for children with a chronic condition or complex needs (see Chapter 10). The added value of professionals with different skills working closely together was rated as important (see Chapter 13). However, our survey showed a large variability in opinions on the feasibility of changing towards 
multidisciplinary teams. Some stakeholders thought their country was too far away from the model and believed working in teams costly and in some cases, unnecessary. Stakeholders advocated the importance of understanding the families' perspective and providing clear information to them about how and where to address their healthcare needs. We know that special attention should be given to vulnerable families with complex needs, particularly those who do not have the capacity to organise their help in a sufficient way (Chapters 5 and 15; Keilthy, Warters, Brenner, \& McHugh, 2017). It was generally agreed that facilitating the different professionals working together would be a challenge and that training in multidisciplinary working would be beneficial (see Chapter 13) (Brenner, O’Shea, \& Larkin, 2017).

\section{Early Recognition of Mental Health Problems in Adolescents}

The stakeholders supported collaboration and communication between healthcare providers as components of health care that should be optimised in order to improve early recognition of mental health problems in adolescents. The majority of stakeholders also replied that they were positive about confidential access to adolescent health service; however, we received a variety of opinions on the subject. Some stakeholders thought guaranteeing confidentiality to adolescents when consulting primary care improves early recognition of mental health problems, through lowering the barrier to approach care and increasing the willingness of adolescents to discuss sensitive topics. Other stakeholders expressed their doubts or were against confidential access. They thought this hampers the inclusion of the family in the treatment process, which is considered key to optimal service delivery to adolescents with mental health problems. The stakeholders were clear at what stage of the patient consultation confidentiality can be given: namely in preventive activities, all kinds of psychological support and training or courses that are available for all children. However, for treatment of complex problems, medical treatment and prescription of medicines, consent of parents is needed and confidentiality cannot be given.

\section{Feasibility, Barriers and Facilitators: Criteria for Transferability}

The stakeholders of open-access countries seemed to answer most frequently to have a need for a change of the system. They were relatively more often in favour of a change than the two gatekeeper system countries across all three scenarios. The stakeholders from gatekeeper and mixed-led countries asked the least for a change towards confidential access. The primary care systems for children in countries with a gatekeeper function by GPs seemed to need the least amount of change (this applies to specialised preventive health services and multidisciplinary teams). The stakeholders from these countries indicated most often that the suggested scenario was already in place in their country.

The differences between care systems make clear that transferring an optimal model requires tailoring to the specific country-setting. The following criteria 
from the PIET-T process model seemed important (Schloemer \& SchröderBäck, 2018).

\section{Population Characteristics}

Public attitude towards a health topic seemed to be important for change to be effective and for equitable service delivery (see Chapter 17). This is particularly relevant for issues such as vaccination, the way of accessing services and the age in which a young person can make use of a service without parental consent. MOCHA's research into public preferences for primary care for children showed large differences between countries in terms of respondents' agreement on the statement whether the child has the right to a confidential consultation with a primary care provider (Van Til, Groothuis-Oudshoorn, \& Boere-Boonekamp, 2018). Samples from populations from Spain and Poland (gatekeeper and mixed-led country, respectively) agreed the least with this right for children, which corresponded with the views of the experts in study. As the public attitudes on, for instance, family involvement in the care of a child vary between countries, transferability of a healthcare system from one country to another very much depends on these opinions being embedded in the countries' culture (Zdunek, Schröder-Bäck, Blair, \& Rigby, 2017).

\section{Environment}

In all scenarios, the current healthcare system and service provision in the country was regarded as a major barrier for moving towards the proposed changes in the systems' components. Relatively, the least challenging change was towards multidisciplinary working, although the issue of financing multidisciplinary teams, the slow process of changing the policy and legislation and the general need for more workforce was nevertheless mentioned as barriers. A well-functioning and accessible healthcare system was also seen as a facilitator in the sense that well-equipped school health services add to the early recognition of mental health problems in adolescents. The MOCHA project has demonstrated the value of extensive national policies, sometimes as shared responsibility with regional authorities, with regard to school and adolescent health services as an indicator for countries to have potentially good quality services for children and adolescents (see Chapter 11) (Jansen et al., 2018). National policies to ensure geographical and financial access were also identified by the PHAMEU project, as indicators for the presence of strong primary care in a country (Kringos et al., 2013).

\section{Intervention Content}

A facilitating factor mentioned several times by the stakeholders was the evidence base with regard to the targeted changes of improved communication on vaccination and confidential access to adolescent health services. With regard to the importance of interdisciplinary working for an effective primary healthcare system, the evidence base was already there according to the stakeholders. The 
importance of good e-health systems, such as patient record systems for coordination of care and reminder systems for vaccinating children, was also mentioned several times as a facilitator. A lack of evidence on the influence of such systems on the effectiveness, efficiency and quality of primary care hinders further development of the care system. Conducting research to find the evidence will facilitate changes in components of primary care.

\section{Transfer}

Favourable economic conditions, supportive policy-making and a good political climate will facilitate the sustainability of transfer of optimum components of primary care from one country to another (Schloemer \& Schröder-Bäck, 2018). The barriers found in our study, such as lack of funding and a lack of qualified professionals need to be addressed in clear strategies and policies.

\section{Expert Views on Implementation of Good Practices}

This study went in more in depth what factors influence the implementation of good practices in primary child health care. Knowledge of these factors from the PIET-T model informs us whether transferability of optimal component to a specific healthcare system or country may be possible (Van Kesteren, Van Zoonen, Kocken, 2018). The study aimed to:

- obtain insight into the availability and use of good practices of measles immunisation, information provision on contraceptive advice for adolescents, assessment of mental health problems and asthma care in six European countries; and

- achieve a better understanding of the facilitators and barriers of implementation of suggested good practices within the context of various models of primary child care in Europe.

A cross-case research design was used to compare implementation conditions between good practices and countries. The experts were asked to fill out an online questionnaire to get insight into their views with regard to the use of good practices, barriers and facilitators. Experts from six European countries were included in this study: Germany, Cyprus, Sweden, The Netherlands, Italy and Poland. Countries were selected in such a way that they were more or less exemplary of the broad features of the types of primary care models in the EU (see Chapter 1). They varied in terms of lead practitioner (GP, primary care paediatrician, mixed) and open or gatekeeping systems of provision of health services. For this study, we added a third governance characteristic, namely whether the health care is state regulated or professionals have more or less autonomy in providing services, respectively, hierarchical or non-hierarchical systems (Bourgueil, Marek, \& Mousquès, 2009).

The results give insight into the availability and use of guidelines and formal procedures, barriers and facilitators of implementation of the good practices 
studied and similarities and differences between good practices and models of child primary care.

\section{Availability and Use of Guidelines and Formal Procedures}

The influence of the type of primary care model on the availability of guidelines or formal procedures was studied. In general experts from Sweden, the Netherlands and Poland, with a hierarchical gatekeeping system seemed to be positive about the availability of guidelines. Non-hierarchical led countries seemed to have guidelines to a lesser extent. In Cyprus, a country with open access and where paediatricians deliver primary care for children, guidelines were the least available. Germany as a country with similar system characteristics was divergent in this respect and had guidelines available. It appeared that all countries have guidelines or formal procedures available for asthma, but that in spite of their availability, the use of these guidelines or formal procedures was limited. In contrast, guidelines or formal procedures for immunisation were generally used for nearly all children and the best implemented.

\section{Barriers and Facilitators of Implementation of the Good Practices Studied}

We examined barriers and facilitators of the implementation process of good practices related to a framework representing the implementation process and related categories of determinants, namely characteristics of the good practice itself (intervention content), the primary care professional, the organisational setting and the socio-political context (environment) (Fleuren et al., 2004; Schloemer \& Schröder-Bäck, 2018).

The results showed that experts from most countries identified mostly facilitators with regard to communicating with vaccine-hesitant parents; barriers were notably found with regard to the conduct of spirometry for asthma and for conducting a psychosocial assessment for contraceptive services for sexually active adolescents.

Important facilitators at the level of the intervention were that the good practice is not too difficult to perform and fits well within routine practice such as with vaccination. Facilitators from the environment were the perception of the primary care professional that it is important to use good practice and that the good practice is supported by healthcare policy-makers. This was also especially the case with vaccination.

Important barriers that were mentioned by experts from almost all countries were in the field of financial resources and time available, knowledge and adequate training for doctors and nurses. With regard to performing spirometry for asthma diagnosis and management, some experts saw barriers were on the socio-political level with regard to policy support and legislation and regulation. With regard to the implementation of the good practice of conducting a psychosocial assessment in order to provide contraceptive information and services for sexually active adolescents, the experts identified mainly barriers. For 
conducting a risk assessment of the mental health problems in young people, the majority of countries identified both facilitators and barriers.

Poland, Italy, Germany and Cyprus, all countries with a paediatrician- or mixed paediatrician-/GP-led child primary care, experienced facilitators and barriers in the implementation of the good practices. The experts from the Netherlands and Sweden, all countries with hierarchical professional GP-led systems, experienced facilitators to a greater extent, in Sweden particularly in terms of motivating parents to vaccinate their child and use of spirometry.

Immunisation, spirometry and screening for mental health are all are clinical procedures, which have varying levels of complexity. Barriers and facilitators to changes may be understood from the Cynefin model on complexity (IBM) (Snowden \& Boone, 2007). For example, vaccination is a more or less simple practice that can be changed with relative ease. Use of the spirometer in asthma care may be more complicated and dependent on variables which can be managed reasonably well in care, such as resources and professional consensus on the acceptance of the good practice. Risk assessment for mental health and sexual and reproductive health is a more complex good practice, due to the influence of societal, genetic and care determinants. The assessment of these health problems is therefore difficult and can be managed to a lesser extent.

\section{Penalties, Rewards and Behaviour Change}

This strand of the MOCHA programme focussed on the use of levers, which is the term adopted for the use of incentives and penalties to encourage certain choices, in European child healthcare contexts. It is suggested that the use of levers is likely to increase under conditions of neo-liberalism which apply to greater and lesser degrees in all MOCHA countries (Wells, 2017a). Where individuals are encouraged to believe that they should seek out opportunities to choose their own treatment and care, but the state cannot actually allow its citizens to make free choices that are not in the best interests of the wider group (such as in the case of immunisation and herd immunity), levers nudge citizens in particular directions while maintaining the illusion of free choice.

Financial levers in particular are in relatively widespread use across Europe (for both providers of and recipients of health care), combined with an implicit assumption that they were part of a good model of delivery (for more details, see Wells, 2017a). However, the research found very limited evidence of evaluations of levers, with those identified general only adopting a financial 'effectiveness' perspective, and mainly focussed on their use in relation to healthcare providers rather than recipients (Wells, 2017a). We concluded that the use of levers is not sufficiently considered within their particular socio-cultural context (e.g. the different political histories of countries, or the variously constructed relationships between citizens and their respective states). Nor is it being considered as part of complex ecological systems involving triadic relationships between emotional humans (child, parent and healthcare provider) rather than rational homo economicus, potentially leading to unwanted and unintended 
consequences. Identities such as 'professional' (on the provider side) and 'parent' (on the recipient side) may be affronted by the implication that a sum of money may be sufficient to change how we behave (Wells, 2017b). The presence of the child as a third person in a 'deal' between the state and a parent is a particular complication in this context, with parents required to choose whether or not they wish to accept the deal on behalf of a child who the parents may believe will actually be the bearer of any perceived risk (Wells, 2017b). Efforts to encourage parents to vaccinate their children are a particularly salient example of this tension.

A further consideration particularly generated by the use of penalties is the introduction of an instrumental and disciplinary relationship into one that should be characterised by normative commitment and trust. 'Gaming' (Eijkenaar, Emmert, Scheppach, \& Schoffski, 2013; Mannion, 2014) is a term that describes when individuals become focussed on the ends, at the expense of the means. This is more likely where the state is seen to have reframed the interaction between itself and the public, or itself and professional healthcare providers, as instrumental (about gains and losses) rather than as normative (about doing something because it is the right thing to do) (Wells, 2017b).

Our research also suggests that an excessive focus on securing the outcome of behavioural change at the expense of proper consideration of the means - the processes via which the outcomes are achieved - is counterproductive. Systems should not aim to secure discrete changes in behaviour at any cost but instead focus on ensuring that its processes and policies increase the perceived legitimacy of the system and authorities. Ensuring that levers are operating in ways that are seen to be procedurally just (offering opportunities for voice, consistent usage, communication of motivation, respect, fairness and so on) (Lind \& Tyler, 1988; Tyler, 1994) is essential for securing longer-term compliance with the state's objectives via its perceived legitimacy in the eyes of the leverage targets and is also closely related to transferability. The basic antecedents of a procedurally just experience appear to be transferable across demographics and contexts, and the limited application of the concepts in healthcare settings does seem to suggest relevant transferability, though there are suggestions that different value structures between countries may mean that some terms (such as 'fairness' and 'respect' perhaps) may vary according to context and therefore need further consideration (Cohen \& Avrahami, 2006). There is, furthermore, reason for viewing quality patient experiences as a central aspect of any healthcare model, not as an added luxury, given that increased satisfaction also leads to increased compliance with treatment recommendations. Satisfied patients appear, therefore, to be healthier patients, and this is achieved via procedurally just treatment within relationships characterised by trust, respect and lack of bias that, in many cases, can be achieved at little or no extra cost to the system. Conversely, the costs to health (in the short and long term) of accidentally designing systems that do not value procedural justice are likely to be significant. These procedural justice considerations should be a facet of all levering policies and not be overlooked in pursuit of short-term targets for compliance. There is no point securing shortterm behavioural change if the means of doing so alienate the provider or 
recipient from (all) authority in future and make them less compliant in the longer term (Hughes \& Larson, 1991). It is necessary to see attempts at leverage as conveying messages about value, worth and respect to their intended recipients, not just as methods of securing behavioural change. For example, behavioural change approaches may tell us that people are more likely to be amenable to making changes at key life points such as when they become parents, or experience bereavement, but we should look to procedural justice approaches of basic fairness and equity of provision (Lind \& Tyler, 1988; Tyler, 1994) to guide a healthcare system in targeting potentially vulnerable people in ways that do not make them feel exploited.

The MOCHA research also highlights significant equity issues relating to financial and intellectual resources, given that within any population not everyone has the same capacity to (1) understand what is being offered or threatened and in relation to what activity and (2) freely choose whether or not they wish to accept the offer, or endure the threat, that the state is making (e.g. where less wealthy parents may have to factor in financial benefit or hardship, while more wealthy parents may not) (Wells, 2017a).

As such, it is vital that the future use of levers is not underpinned by an assumption that behavioural change can be achieved through the manipulation of rational actors (and hence a neglect of issues such as emotion, capacity, justice and socio-cultural context). There are ways in which the use of levers can be rendered more procedurally fair, and more likely to secure longer-term compliance, but equity issues are likely to remain wherever resources and access are offered or withheld as a method of securing compliance with state objectives.

\section{Summary}

The MOCHA research presented in this chapter assessed criteria for transferability of models of primary child health care from one setting or country to another. It showed that stakeholders expressed a need for improvements to the child primary care system and valued the importance of system components in the field of public access to information about vaccination, coordination and continuity of care and open access to services for adolescents and confidentiality until treatment is in place. Heterogeneity was found between countries with regard to the presence of these components and their demand for change. Primary care systems with open access seemed to have the highest demand for changing system components. GP-led gatekeeper systems, generally rated as strong primary care systems, felt the least urgency for transforming system components.

The study into factors affecting the implementation of good practices also showed that models of primary care to a certain extent are relevant. It was found that GP- or mixed-led hierarchical professional systems seemed to have a positive influence on the availability of guidelines of formal procedures for several good practices. It is likely that governance features are important to ascertain the needed levels of guideline use and adherence. Good practices in the field 
of immunisation, asthma care and screening for mental health or reproductive issues are all clinical procedures with varying levels of complexity, requiring appropriate resources, training and public information and cultural 'acceptance' from a public and professional perspective. Guideline adherence to optimise effectiveness may be more likely in hierarchical professional systems with a certain level of state regulation.

With regard to the PIET-T criteria, public attitudes towards a health topic are important for changes with regard to effective vaccination coverage or service use without parental consent. Also, the current healthcare system and service provision in a country is regarded as a major facilitator or barrier for moving towards changes in the systems' components. A facilitating factor in the field of intervention content mentioned is the evidence base with regard to the targeted change. The study of good practices showed that the implementation is influenced by a range of facilitating or hindering factors that fall in the broad PIET-T categories intervention content and environment, such as service organisation and socio-political factors. The perceived legitimacy of levers for behaviour change of countries' citizens is reflected in the socio-cultural context and people's perceptions of the PIET-T model. Healthcare systems should not aim at securing discrete changes in behaviour at any cost but instead focus on ensuring that its processes and policies increase the perceived legitimacy of the system and authorities.

This chapter makes clear that transfer of an optimal model requires tailoring to the specific country-setting. It is important to be aware of the sensitivity of the population and environmental characteristics of a country and monitor them before starting changes to the system of primary child health care.

\section{References}

Blair, M., Rigby, M., \& Alexander, D. (2017). Final report on current models of primary care for children. Retrieved from www.childhealthservicemodels.eu/wp-content/ uploads/2017/07/MOCHA-WP1-Deliverable-WP1-D6-Feb-2017-1.pdf

Bourgueil, Y., Marek, A., \& Mousquès, J. (2009). Three models of primary care organization in Europe, Canada, Australia and New-Zealand. Institute for research and information in health outcomes, Issues in health economics, 141.

Brenner, M., O'Shea, M., \& Larkin, P. (2017). Final report on the current approach to managing the care of children with complex care needs in member states. Retrieved from http://www.childhealthservicemodels.eu/wp-content/uploads/2015/ 09/20170725_Deliverable-D8-2.1-Final-report-on-the-current-approach-to-managingthe-care-of-children-with-complex-care-needs-in-Member-States.pdf

Cohen, A., \& Avrahami, A. (2006). The relationship between individualism, collectivism, the perception of justice, demographic characteristics and organisational citizenship behaviour. The Service Industries Journal, 26(8), 889-901. doi:10.1080/ 02642060601011707

Damschroder, L. J., Aron, D. C., Keith, R. E., Kirsh, S. R., Alexander, J. A., \& Lowery, J. C. (2009). Fostering implementation of health services research 
findings into practice: A consolidated framework for advancing implementation science. Implementation Science, 4, 50-65. doi:10.1186/1748-5908-4-50

Eijkenaar, F., Emmert, M., Scheppach, M., \& Schoffski, O. (2013). Effects of pay for performance in health care: A systematic review of systematic reviews. Health Policy, 110, 115-130. doi:10.1016/j.healthpol.2013.01.008

Fleuren, M. A. H., Wiefferink, K., \& Paulussen, T. (2004). Determinants of innovation within health care organizations: Literature review and Delphi study. International Journal for Quality in Health Care, 16, 107-123. doi:10.1093/ intqhe/mzh030

Hughes, T., \& Larson, L. (1991). Patient involvement in health care: A procedural justice viewpoint. Medical Care, 29(3), e159-e165.

Jansen, D. E. M. C., Visser, A., Vervoort, J. P. M., van der Pol, S., Kocken, P., Reijneveld, S. A., \& Michaud. (2018). School and adolescent health services in 30 European countries: A description of structure and functioning, and of health outcomes and costs. Retrieved from http://www.childhealthservicemodels.eu/wp-content/ uploads/Deliverable-173.1_Final-report-on-the-description-of-the-various-models-ofschool-health-services-and-adolescent-health-services.pdf

Keilthy, P., Warters, A., Brenner, M., \& McHugh, R. (2017). Final report on models of children's social care support across the EU and the relationship with primary health care. Retrieved from http://www.childhealthservicemodels.eu/wp-content/ uploads/2017/07/20170728_Deliverable-D9-2.2-Final-report-on-models-of-children $\% \mathrm{E} 2 \% 80 \% 99$ s-social-care-support-across-the-EU-and-the-relationship-with-primaryhealth-care.pdf

Kocken, P., Vlasblom, E., De Lijster, G., \& Reijneveld, M. (2018). A report containing consensus statements on most optimal models with guidance on potential benefits and how these might be achieved. Retrieved from http://www.childhealthservicemodels.eu/wp-content/uploads/Deliverable-D18-9.2-A-report-containing-consensusstatements-on-most-optimal-models-with-guidance-on-potential-benefits-and-howthese-might-be.pdf

Kringos, D. S., Boerma, W. G., Hutchinson, A., Van der Zee, J., \& Groenewegen, P. P. (2010). The breadth of primary care: A systematic literature review of its core dimensions. BMC Health Services Research, 10(1), 65. doi:10.1186/14726963-10-65

Kringos, D., Boerma, W., Bourgueil, Y., Cartier, T., Dedeu, T., Hasvold, T. ... Groenewegen, P. (2013). The strength of primary care in Europe: An international comparative study. British Journal of General Practice, 63(616), e742-50. doi:10.3399/bjgp13X674422

Lind, E., \& Tyler, T. (1988). The social psychology of procedural justice. London: Plenum Press.

Mannion, R. (2014). Take the money and run: The challenges of designing and evaluating financial incentives in healthcare; Comment on "Paying for performance in healthcare organisations". International Journal of Health Policy Management, 2(2), 95-96.

Schloemer, T., \& Schröder-Bäck, P. (2018). Criteria for evaluating transferability of health interventions: A systematic review and thematic synthesis. Implementation Science, 13(1), 88. doi:10.1186/s13012-018-0751-8

Schollin Ask, L., Hjern, A., Lindstrand, A., Olen, O., Sjogren, E., Blennow, M., Örtqvist, A. (2017). Receiving early information and trusting Swedish child health 
centre nurses increased parents' willingness to vaccinate against rotavirus infections. Acta Paediatrica, 106(8), 1309-1316. doi:10.1111/apa.13872

Snowden, D. J., \& Boone, M. E. (2007). A leader's framework for decision making. Harvard Business Review, 85(11), 68-76.

Tyler, T. (1994). Psychological models of the justice motive: Antecedents of distributive and procedural justice. Journal of Personality and Social Psychology, 67(5), $850-863$.

Van Kesteren, N. M. C., Van Zoonen, R., \& Kocken, P. L. (2018). Validated optimal models of children's prevention orientated primary health care: An E-Book showcasing conditions for implementation of examples of good practices in primary child health care in European countries. Retrieved from http://www.childhealthservicemodels.eu/wp-content/ uploads/20180131_Deliverable-D15-9.1-An-e-book-showcasing-conditions-for-implementation-of-examples-of-best-practices-in-primary-child-health-care-in-Europe-v2.pdf

Van Til, J., Groothuis-Oudshoorn, K., \& Boere-Boonekamp, M. M. (2018). Public priorities for primary child health care for children. MOCHA. Retrieved from http://www.childhealthservicemodels.eu/wp-content/uploads/member-files/FinalReport-POCHA_14-08-2018.pdf

Wells, H. (2017a). Contribution to Blair, M., Rigby, M., Alexander, D. (2017) Final report on current models of primary care for children. Part I. Chapter 8 . Retrieved from www.childhealthservicemodels.eu/wp-content/uploads/2017/07/MOCHAWP1-Deliverable-WP1-D6-Feb-2017-1.pdf

Wells, H. (2017b). Contribution to Contribution to Blair, M., Rigby, M., Alexander, D. (2017) Final report on current models of primary care for children. Part II. Chapter 8. Retrieved from www.childhealthservicemodels.eu/wp-content/uploads/ 2017/07/MOCHA-WP1-Deliverable-WP1-D6-Feb-2017-1.pdf

Zdunek, K., Schröder-Bäck, P., Blair, M., \& Rigby, M. (2017). Report on the contextual determinants of child health policy. Retrieved from http://www.childhealthservicemodels.eu/wp-content/uploads/member-files/Context-Culture-ReportWP-1-task-7-a-12.03.2017.-PRE-FINALdocx.pdf 